DOI: 10.1002/berj.3326

\title{
Editorial
}

\section{Why the nature of educational research should remain contested: A statement from the new editors of the British Educational Research Journal}

\author{
David Aldridge, Gert Biesta, Ourania Filippakou and Emma \\ Wainwright \\ Brunel University London, London, UK
}

We are delighted to have been invited to edit the journal by the British Educational Research Association (BERA). As we begin our custodianship, we want to engage with a set of questions that emerges from the state of contemporary education: What counts as educational research? What, for that matter, counts as education? Is there a 'gold standard' of educational research? Who is best placed or best qualified to carry out educational research? Who are the readers of our journal and how do they read it? How can a journal focusing on the four nations of Britain also serve an international academic community?

The journal that we are inheriting from the previous editorial team is in excellent shape, which puts us in a strong position to address the transforming international context of educational research, policy and practice. Our vision is that BERf retains its hallmark of excellence and continues to showcase the best British and international research in education. At the same time, we hope that the journal will set the agenda for exploring the boundaries of educational research, how educational research relates to policy and practice, and who educational research is produced by and for.

The editors of an academic journal in any field right now must also ask an additional set of questions: What is a journal and what is its role in the present academic and professional climate? What are the implications for a journal, and the field it serves, of open access, changes in forms of electronic publishing, and interaction with social media? Who reads an academic journal and how do readers find and access a particular article? The days when anyone 'reads' a single paper issue of a journal from cover to cover are surely numbered. Do we even need academic journals any more?

We acknowledge that the field and disciplines of educational research, and the publishing practices that have traditionally served them, are in question. This presents challenges and opportunities for the journal. We believe that $B E R \mathcal{F}$ will maintain its brand of academic excellence throughout these transforming circumstances by being self-reflexive, and by encouraging submissions that question the nature of research and of the disciplines that contribute to our understanding of education. Our hope is 


\section{Editorial}

to lead a journal that will be recognised as a reflection on as well as of the field of educational research.

The increasing international interest in evidence-based policy over the last two decades has been accompanied by a narrowing in the kinds of research that policy makers often seem to be prepared to accept as evidence for what works in educational contexts. At the same time, grassroots teacher movements such as the increasingly international entity that is ResearchEd have joined the call for research into educational effectiveness that can be easily accessed, digested and put to use by practitioners. Attempts in various national contexts to establish the randomised control trial as the 'gold standard' for educational enquiry have fuelled hopes for the establishment of an educational science oriented towards social improvement. But such moves have also met with resistance and criticism from academics and practitioners across these national settings.

We appreciate the need to engage with the public debate about the accessibility of educational research and the communities that are best situated and qualified to carry it out. As a generalist journal, we need to invite conversation on educational questions from colleagues working in different disciplines and on different phases and forms of education - schooling, further education, higher education - and on both formal and informal educational contexts. As an education journal, we need to reach out and relate to practitioners and the various professional communities with which they identify, seeking to understand what they need from research, while also continuing to ensure high standards of research quality.

The nature and size of the part that educational research can play in the 'education debate' is a highly contested question across many quarters of society and academic endeavour. It is fitting and essential that this question should be asked in and around the pages of this journal. As editors, we do not represent a particular position on this question so much as a commitment to establishing and preserving the journal as a location where the question can be debated with sophistication. On this matter, certainly, we are partisan: this question has not been settled and is not likely to be any time soon.

We therefore propose a distinctive vision for the next phase of the journal's development that acknowledges the journal's responsibility (i) to its readers, (ii) to the field of educational research and (iii) to its authors.

(i) Our Readers. The journal must actively address the increasing demand for the accessibility and relevance of educational research. This certainly means helping readers to locate the work that speaks to their existing questions and concerns. But it also means inviting them into the debate about what education is and what educational researchers do. We propose a more explicit social media strategy to direct attention to new publications and accompanying online material. We will develop a closer relationship between the journal and the BERA blog, encouraging the authors of published papers to take this opportunity to explain and promote their work. We propose to continue and increase the curation of virtual special issues that showcase the journal's past publications, alongside relevant contemporary commentary and reflection. We will consider reintroducing special issues on current themes and concerns, which would contribute to the journal's interest 
value for an international general readership interested in contemporary educational issues.

(ii) The Field of Educational Research. The specific contribution of this journal can be to ensure high standards in the practice, dissemination and interrogation of educational research regardless of discipline, and to be a site for communication across the different phases and forms of educational research. The standards we wish to uphold are those of ethical and intellectual integrity. We seek to promote research that recognises the theoretical assumptions researchers have made about the nature and aims of educational activity. We hope that the reflexive nature of the journal will encourage contributing authors not to assume a privileged 'gold standard', but to be prepared to ask difficult questions about the nature and role of evidence across the different domains of educational enquiry, to be able to justify a particular approach to educational enquiry and recognise its limits. At this point we would also like to explicitly challenge a perception that the journal promotes any particular methodology. We welcome contributions from the broadest range of approaches to research. We want the journal's editorial activity to keep open debates about the nature, scope and value of educational research, and would resist attempts to privilege evidential concerns over the normative, or the practical over the theoretical. We aim to increase the proportion of work that considers educational questions in their full range of ethical, political and theoretical significance.

(iii) Our Authors. This is a generalist journal but we acknowledge that educational research is often conducted within a specific educational phase or context and from a particular disciplinary perspective. We encourage the submission of work that concentrates on a particular national context or educational phase, or that represents a specialised disciplinary approach, provided that it raises or addresses questions that are of interest to the broader educational community. Our criterion for specialist work is that it has the potential to engage with researchers working in different disciplines and on different educational contexts. We do not wish to publish history papers (for example) that speak to issues that are only of interest to other historians, or psychology papers that only speak to psychologists - but we do want to publish specialist work that speaks to broader educational concerns and seeks to reach a wider audience. We hope to maintain the diversity of topics and perspectives that is a recognisable feature of the back cover of any recent issue of the journal.

We also recognise the journal's international reach and would like to acknowledge what goes along with the aspiration to be part of a global community: this further brings into question assumptions about the nature, scope and form of educational research, as we are aware that the particular way in which the field of educational research has been configured in the English-speaking world (often relying on disciplinary perspectives) is significantly different from how educational research is conducted in other linguistic and national settings (where it often has established a disciplinary status of its own). We will continue to encourage work that investigates contexts other than the British, where it has the capacity to engage with or inform our generalist international readership, particularly on this reflexive question of how it is 


\section{Editorial}

that educational researchers can learn from each other across different national, cultural and intellectual contexts.

Our proposal can be summarised thus: we are 'open for business' for article contributions from across the wide range of educational research and scholarship, as long as this work speaks to the wider educational community —of researchers, practitioners and policy makers. In addition, we commit to pro-actively pursuing the ongoing discussion about what counts or should count as educational research. It is important to us that educational research remains contested.

London, January 2018 